ently after the development of the fetal thyroid (10 weeks' gestation), radioiodine is associated with ablation of the thyroid, congenital hypothyroidism, and, in some cases, mental retardation. ${ }^{15}$ None the less, if steps are taken to ensure that the patient is not pregnant at the time of treatment and avoids pregnancy for the next four months until the potential for fetal irradiation has disappeared there is no evidence for a significantly increased risk of congenital abnormality arising from gonadal irradiation.

The theoretically increased risk of genetic abnormality from radioiodine treatment in either sex has been estimated at $0.005 \%{ }^{16}$ - unsurprisingly, such a risk has not been identified even in large studies. Much larger doses of radioiodine have been given to adolescents with thyroid cancer without abnormalities in offspring. ${ }^{17}$ Reviews of the reproductive history of those receiving radioiodine for thyrotoxicosis, or larger doses for thyroid cancer, have also failed to show a subsequent risk of infertility. ${ }^{1+}$ Furthermore, patients irradiated during routine radiographic examinations receive similar gonadal doses to those receiving radioiodine therapeutically; such doses are considerably lower than those predicted to cause infertility, ${ }^{18}$ so that this is not a concern in the treatment of thyrotoxicosis.

Despite the evidence that radioiodine is a safe treatment for thyrotoxicosis enthusiasm for its use differs between centres and countries. A recent survey found that one third of American doctors regarded radioiodine as the right treatment for a 19 year old woman presenting with moderately severe thyrotoxicosis; the corresponding European figure was $4 \%$. Since the age restrictions on the use of radioiodine were removed in Britain in 1983, all those with thyrotoxicosis in this country may now receive this treatment. Though it remains our general policy in Birmingham to treat young patients at presentation with a 12 month course of antithyroid drugs and to proceed to radioiodine on relapse, we have found radioiodine increasingly useful in the initial management of young patients with thyrotoxicosis. Despite general concerns regarding the effects of radioactivity radioiodine is likely to become an increasingly popular treatment for thyrotoxicosis because of its safety, efficacy, and ease of administration.

JAYNE FRANKLYN Senior Lecturer in Medicine

MICHAEL SHEPPARD

Professor of Medicine

Birmingham University, Queen Elizabeth Hospital,

Birmingham B15 2TH

1 Tunbridge WMG, Evered DC, Hall R, Appleton D, Bruwis M, Clarke F, et al. The spectrum of thyroid disease in a community. Clin Endocrinol 1977;7:481-93.

2 Allanic H, Fauchet R, Orgiazzi J, Madec AM, Genetet B, Lorcy Y, et al. Antithyroid drugs and Graves' disease: a prospective randomized evaluation of the efficacy of treatment duration. $\mathcal{F}$ Clin Endocrinol Metab 1990;70:675-9.

3 Hashizume K, Ichikawa K, Sakurai A, Suzuki S, Takeda T, Kobayashi M, et al. Administration of thyroxine in treated Graves' disease. Effects on the level of antibodies to TSH receptors and on therisk in treated Graves disease. Effects on the level of antibodies to TSH

4 Wartofsky L, Glinoer D, Solomon D. Differences and similarities in the diagnosis and treatment of Graves' disease in Europe, Japan, and the United States. Thyroid 1991;1:129-35.

5 Franklyn JA, Daykin J, Drolc Z, Farmer M, Sheppard MC. Long-term follow-up of treatment of thyrotoxicosis by three different methods. Clin Endocrinol 1991;31:71-6.

6 Turner J, Sadler W, Brownlie B, Rogers T. Radioiodine therapy for Graves' disease: multivariate analysis of pretreatment parameters and early outcome. Eur $\mathcal{F}$ Nucl Med 1985;11:191-3.

7 Sridama V, DeGroot L. Treatment of Graves' disease and the course of ophthalmopathy. Am $\mathcal{Y} \mathrm{Med}$ 1989;87:70-3.

8 Utiger RD. Treatment of Graves' ophthalmopathy. $N$ Engl F Med 1989;321:1403-5.

9 Spencer RP, Chapman CN, Rao H. Thyroid carcinoma after radioiodine therapy for hyperthyroidism: analysis based on age, latency and administered dose of I-131. Clin Nucl Med 1983;8:216-9.

0 Dobyns BM, Sheline GE, Workman JB, Thompkins EA, McConatey M, Becker DU, et al Malignant and benign neoplasms of the thyroid in patients treated for hyperthyroidism: a report of the co-operative thyrotoxicosis therapy follow-up study. $f$ Clin Endocrinol Metab 1974;38:976-8.

11 Hall P, Boice JD, Berg G, Bjelkengren G, Ericsson U-B, Hallquist A, et al. Leukaemia incidence after iodine-131 exposure. Lancet 1992:340:1-4.

2 Sheppard MC. Radioiodine therapy for thyrotoxicosis and risk of malignancy. In: Rubery E, Smales E, eds. Iodine prophylaxis following nuclear accidents. London: Pergamon, 1988:111-8.

Goldman MB, Maloof F, Monson RR, Aschengrau A, Cooer DS, Ridgway EC. Radioactive iodine therapy and breast cancer. Am $\mathcal{Y}$ Epidemiol 1988;127:961-90.

4. therapy and breast cancer. Am f Epidemiol 1988;127:961-90. adolescents treated with radioactive iodine for hyperthyroidism. N Engl $f$ Med 1975;292:167-71. adolescents treated with radioactive iodine for hyperthyroidism. $N$ Engl $\mathcal{F}$ Med $1975 ; 292: 167-71$.
Stoffer SS, Hamburger J. Inadvertent 131-I therapy for hyperthyroidism in the first trimester of Stoffer SS, Hamburger J. Inadvertent 131-
pregnancy. F Nucl Med 1975;17:146-9.

16 Robertson JS, Gorman CA. Gonadal radiation dose and its genetic significance in radioiodine therapy of hyperthyroidism. $\mathcal{F}$ Nucl Med 1976;17:826-35.

17 Sarker SD, Beierwaltes WH, Gil SP, Cowley BJ. Subsequent fertility and birth histories of children and adolescents treated with 1311 for thyroid cancer: $\mathcal{O}$ Nucl Med 1976;17:460-4.

18 Non-stochastic effects of ionizing radiation. Annals of the International Commission on Radiological Protection 1984;14: No 3.

\title{
Euthanasia: time for a royal commission
}

\section{The tide seems to be running for euthanasia}

It is time for the British to think deeply about euthanasia. The trial and conviction of rheumatologist Nigel Cox for attempted murder after giving a terminally ill patient a lethal injection has given the debate over euthanasia an almighty shove ( $p 731) .{ }^{1}$ The mood of the nation seems to be that the conviction may have been legally correct but that to destroy a caring doctor through such a trial was wrong: jurors burst into tears; the judge said that criminal trials could sometimes be an "overwhelming burden"; and the family wished that the trial had never happened. The law is in effect the codification of the will of the people, and when there is such tension between a legal verdict and the people's thinking then it is time to reconsider the law. A royal commission is the best way that the British have to examine such a difficult but universally important issue.

Dr Cox's case may well prove to be a watershed. Euthanasia is rising up the agenda in many countries. In November 1991 the people of Washington state voted narrowly against a proposal to permit a "medical service provided in person by a physician, that will end the life of a conscious and mentally competent qualified patient in a dignified, painless and humane manner." As the BMJ's international round up earlier this year made clear, ${ }^{1 \mathrm{a}}$ California and Oregon will hold similar referendums soon. ${ }^{2}$ In Britain the number of people agreeing with the statement "Some people say that the law should allow adults to receive medical help to an immediate peaceful death if they suffer from an incurable illness that is intolerable to them, provided that they have previously requested such help in writing" rose from $69 \%$ (95\% confidence interval $67 \%$ to $71 \%$ ) in 1976 to $75 \%$ in $1989(73 \%$ to $77 \%$ ) in $1989 .{ }^{3}$ Similar trends have been shown in Canada and Australia.

This slow but steady change in public opinion is reminiscent of what happened with abortion: in the past 30 years many countries have moved from extremely restrictive to liberal laws on abortion, and over the next 30 euthanasia may move from being covert to being legal. Dr Cox's case may then rank alongside those of doctors charged with procuring abortion in women who otherwise faced death from their pregnancies. In many countries suicide has been through the same passage from unacceptability to legality.

And not only the people are changing their views: politicians, bioethicists, and doctors are also changing. In Britain an all party group of members of parliament and peers has 
been formed to review the case for legalising euthanasia, ${ }^{4}$ and the group will introduce a bill on advanced directives into parliament later this year. ${ }^{5}$ The Voluntary Euthanasia Society says that at least 90 members of parliament are sympathetic to its cause. Some ethicists have long supported euthanasia, setting greater store by patients' autonomy to decide that enough is enough than by any moral precept of the sanctity of life. More perhaps than any other, Britain is a post-religious society, where theological notions like the sanctity of life should not be overvalued. But many ethicists have been deeply worried by the difficulties of framing a law on euthanasia and by the possibility that patients might be pressured by relatives or others to agree to euthanasia; they have thus agreed that not prolonging life is acceptable, whereas actively terminating it is not. This was also the line taken by the BMA in its last report on euthanasia, ${ }^{6}$ but the philosophy that supports drawing this line is distinctly shaky. ${ }^{78}$ More and more doctors do seem to consider euthanasia acceptable in strictly defined circumstances. This form of death has become common in the Netherlands, where it is allowed, ${ }^{9}$ and a survey of 2000 doctors in Victoria found that 869 supported euthanasia. ${ }^{10}$ But even people who intellectually support euthanasia may find that they feel differently when they experience the death of a spouse - as the personal view from $F$ W Fairhead on p 780 shows. ${ }^{11}$

Last week also saw the publication of the report of the Appleton international conference on developing guidelines for decisions to forgo life-prolonging medical treatment. ${ }^{12}$ This conference, which brought together the views of 1450 people from 15 countries, concluded: "requests for active termination of life by a medical act which directly and intentionally causes death may be morally justifiable and should be given serious consideration." Some people dis- sented from this guideline, but others were worried that the constant unwillingness of legislatures to endorse euthanasia may lead to increasing euthanasia "through the back door" and "a dangerous trend towards acting in the face of existing legislation." More and more doctors are willing to say anonymously that they have on occasion taken active steps to hasten death. ${ }^{13}$

Britain needs a royal commission and possibly subsequent legislation to bring the law in step with modern thinking and to clarify what is acceptable. The commission would also want to consider advanced directives and issues like withdrawing treatment from patients with the persistent vegetative state (p 732). ${ }^{14}$ There is an urgency to the need for a commission as one effect of last week's case is likely to be that patients will be terrified of talking to doctors about the possibility of their deaths being hastened. And dying alone afraid of talking to your carers may be much worse than being dead.

Editor, $B M \mathcal{F}$

RICHARD SMITH

1 Morris M. Washington state rejects euthanasia. BMf 1991;303:1223.

a Dyer C. Rheumatologist convicted of attempted murder. BMF 1992;305:731.

Campbell CS. "Aid-in-dying" and the taking of human life. f Med Ethics 1992:18:128-34.

3 Helme T. Euthanasia around the world. BMf 1992;304:717.

4 Warden J. Euthanasia around the world: Britain. BMF 1992;304:9-10.

Tonks A. Advanced directive bill. BMJ 1992;305:139.

6 Working Party to Review the British Medical Association's Guidance on Euthanasia. The euthanasia report. London: BMA, 1988.

Higgs R. Not the last word on euthanasia. BMF 1988;296:1348.

8 Rachels J Active and passive euthanasia. $N$ Engl f Med 1975;292:78-80.

Rellema H. Euthanasia around the world: Netherlands. BMF 1992:304:7.

9 Hellema H. Euthanasia around the world: Netherlands. BMF 1992;304

Fairhead FW. How much is a hug? $B M \mathcal{F}$ 1992; 305:780.

1 Fairhead FW. How much is a hug? $B M \mathcal{f} 1992 ; 305: 780$.

Stanley JM, ed. The Appleton international conference: developing guidelines for decisions to forgo life - prolonging medical treatment. $\mathcal{F}$ Med Ethics 1992;18(suppl).

3 Kuhse H, Singer P. Doctors' practices and attitudes regarding voluntary euthanasia. Med $\mathcal{J}$ Aus 1988;148:623-7.

14 Dyer C. High Court to rule on right to die case. BMf 1992;305:732.

\section{Managing recurrent malignant pericardial effusions}

\section{Percutaneous balloon pericardiotomy may have a role}

Palliative treatment should be evaluated in the context of the the disease in question. If survival is short a troublesome procedure is unjustified-if it is long then intervening to relieve symptoms may be worth while.

Once a malignant pericardial effusion has been treated, overall survival and quality of life will be determined by the histological type and extent of metastatic disease. Patients with pericardial effusion associated with carcinoma of the lung other than small cell have a median survival of three to four months while for those with carcinoma of the breast it is nine months. Because of the insidious nature of symptoms most malignant pericardial effusions are undetected before death, even though in up to $85 \%$ of cases an effusion may cause death or contribute to the cause of death.

Managing the first episode of symptomatic pericardial effusion with pericardiocentesis seems reasonable (although not all authors agree). Such an approach provides pericardial fluid for analysis and allows the insertion of a percutaneous catheter for drainage and subsequent quantification of pericardial fluid production. Predicting which malignant pericardial effusions will recur, however, is impossible, and deaths have been reported from recurrent tamponade after pericardiocentesis. ${ }^{2}$ Whether an effusion recurs depends on the rate of fluid production, the rate of fluid drainage, and the response of the underlying malignancy to treatment.
Recurrent malignant pericardial effusion presents a clinical challenge. Many alternative approaches to a problem usually indicate the absence of an ideal treatment - which is the case in this condition. Various options include repeat pericardiocentesis, possibly combined with systemic or topical treatment; external beam radiotherapy; and open surgery. While several controlled trials have shown the benefits of sclerosants in managing malignant pleural effusions, ${ }^{3}$ no prospective randomised trial has compared treatments for malignant pericardial effusions. Until such studies have been done we shall have to rely on reports of uncontrolled series to help us choose the best treatment.

The pericardial instillation of the immunomodulator OK $-432^{4}$ (derived from Streptococcus pyogenes A3) and the sclerosants bleomycin ${ }^{5}$ and tetracycline ${ }^{6}$ produces thickening and adhesions of the pericardium, but complications include failure of the procedure, transient pain, fever, arrhythmia, rapid reaccumulation of the fluid, and recurrence of effusion on follow up despite initial success.

Various antineoplastic drugs, radioactive phosphorus ${ }^{32}$, and tumour associated monoclonal antibody radiolabelled with iodine-131 have been instilled into the pericardial space.$^{78}$ This approach seems to be well tolerated systemically and achieves pericardial drug concentrations up to 20 times those achieved by intravenous administration. ${ }^{9}$ Despite this 